revista ANTHROPOLÓGICAS

Ano 25, 32(1): 1-36, 2021

doi.org/10.51359/2525-5223.2021.248380

\title{
Humanos e Caranguejos nos Manguezais do Delta do Parnaíba: histórias da paisagem
}

\author{
Lucas Coelho Pereira ${ }^{a}$ \\ Pedro Castelo Branco Silveira ${ }^{b}$
}

Resumo: A foz do Rio Parnaíba, situada no nordeste brasileiro entre os estado do Piauí e do Maranhão, origina o único Delta das Américas em mar aberto. Esta região apresenta uma rica sociobiodiversidade e exuberantes florestas de manguezais sujeitas a forças de simplificação e contaminação características do antropoceno. O presente artigo narra transformações ocorridas no Delta trazendo a paisagem como protagonista da narrativa a partir das malhas de relações entre caranguejos, manguezais e catadores de caranguejo (caranguejeiros). Por meio de uma abordagem etnográfica que considera as relações entre humanos e outras formas de vida, o artigo evidencia a constituição de paisagens multiespécie frente a processos históricos, e também narrativos, que insistem em eclipsar as diversidades biológicas e culturais. Como contraponto, o artigo enfatiza a dinâmica viva e múltipla da constituição das paisagens do Delta.

Palavras-chave: Manguezais, Caranguejo-uçá, Ucides cordatus, Delta do Parnaíba.

A discussão sobre antropoceno ${ }^{1}$, apesar de relativamente difundida, não é consenso. Para alguns, esta categoria define um momento no qual a presença e atividade humana tornaram-se uma força

\footnotetext{
a Doutorando em Antropologia Social (UnB). Pesquisador vinculado ao Laboratório de Antropologia da Ciência e da Técnica (LACT/UnB). Email: lucascoelhopereira@ gmail.com.

b Doutor em Ciências Sociais (Unicamp). Pesquisador da Fundação Joaquim Nabuco (FUNDAJ-PE). Email: pedrocbsilveira@gmail.com.
} 
assustadoramente destruidora (Kirksey\& Helmreich 2010). Para Donna Haraway (2016), trata-se muito mais de um evento-limite, capaz de alterar o que é e o que virá de forma indelével do que propriamente de uma época. De todo modo, estes/as autores/as nos convidam a colocar a categoria 'humano' em questão e observar mais detidamente tudo aquilo que este 'humano' se recusa a (re)conhecer. Um desses pontos cegos, para Anna Tsing (2015b), seriam as múltiplas temporalidades em paisagens resultantes dos acoplamentos entre humanos e não humanos. Levando a sério este comentário, acompanharemos aqui como paisagens vão se constituindo a partir de uma complexa rede de práticas humanas e mais que humanas.

Pretendemos falar do Delta do Parnaiba - situado no nordeste brasileiro, entre os estados do Maranhão e do Piauí - trazendo a paisagem como protagonista das nossas narrativas. A ideia é percorrer a região partindo dos emaranhamentos históricos e relacionais entre os manguezais, caranguejos e os grupos humanos que vivem da atividade de captura destes crustáceos. Assim seguiremos transformações ocorridas através do tempo e como estas mudanças nos falam de questões caras ao capitaloceno ${ }^{2}$, como a habitabilidade da terra e a maneira como humanos e não humanos se relacionam nestes tempos.

O texto apresenta questões etnográficas a partir da pesquisa de doutorado de um dos autores, Lucas Coelho Pereira, realizada na região do Delta do Parnaíba. As reflexões aqui presentes integram ainda um projeto de pesquisa coletivo do qual ambos os autores fazem parte 'Ecologia política da pesca de crustáceos em manguezais do Nordeste brasileiro' - sob coordenação do outro autor, Pedro Silveira ${ }^{3}$.

Inspirados por Tsing (2015a, 2015b, 2019) entendemos paisagem não como um pano de fundo contra o qual as atividades humanas se desenvolvem, mas como uma assembléia multiespécie e uma composição que emerge com e através das práticas de diversas formas de vida (ver também Cardoso 2018). Ingold $(2002,2015)$ também nos ajuda a pensar sobre a natureza viva e processual das paisagens ao falar de 
como seres humanos e não humanos deixam registros duradouros por onde passam e, assim, constituem paisagens. $\mathrm{O}$ tempo e sua passagem, portanto, são fatores cruciais nesta empreitada. As temporalidades das paisagens são marcadas por um conjunto de atividades relacionadas, mas de ritmos independentes. Paisagens são, assim, fluxos espaço-temporais de práticas relacionais.

Neste sentido, esta categoria significa - para nós - tanto uma estratégia de análise capaz de nos lapidar a atenção para os múltiplos ritmos nos quais os organismos pulsam quanto um artefato empírico. Cientes disso, estamos preocupados com os processos através dos quais o Delta do Parnaíba vai se constituindo a partir dos manguezais, interagindo com forças que teimam em homogeneizá-lo e defini-lo a partir de um único elemento. Pensando com Tsing (2015a, 2015b, 2019) e Haraway (2016), antropoceno também é outro nome para plantationceno, um momento no qual vidas e modos de existências diversos são dizimados em nome de uma padronização produtivista (ver nota 2). Os manguezais, caranguejeiros e caranguejos do Delta do Parnaíba nos contam histórias assim e nos falam, ainda, das suas consequências. Acompanharemos, portanto, a historicidade das paisagens do Delta a partir dos manguezais, seguindo suas transformações e composições em meio à perturbação humana e outras mudanças típicas do antropoceno.

No primeiro tópico, apresentamos a região a partir da literatura científica, mas não só. Enfatizamos as árvores de mangue, as espécies nativas, e a rica biodiversidade na constituição da paisagem. $\mathrm{Na}$ sessão seguinte, manguezais e caranguejos serão articulados pela atividade de captura desses crustáceos: seguiremos guiados pelas conversas e práticas de um de nossos interlocutores. No terceiro tópico, mostraremos como a sociobiodiversidade local passa ao largo de narrativas hegemônicas a respeito da historiografia do Delta, que teimam em narrar paisagens unicamente associadas ao produto econômico da vez. Nossa intenção é mostrar como caranguejos, além de mercadorias, são também uma série de outras coisas. 
Nas três últimas seções discutimos as implicações do antropoceno na constituição de paisagens e como o Delta tem passado, não ileso, por várias mudanças e catástrofes. Passamos pelas transformações ocorridas através da ascensão e queda dos plantios de arroz em áreas de manguezais; pela instituição da Resex Marinha do Delta do Parnaíba e seus diálogos com as pluriatividades do modo de vida ribeirinho, até chegarmos nos atuais desmontes da política ambiental e do grande crime constituído pelo derramamento de petróleo cru no litoral brasileiro em 2019. Fazemos isso dando espaço para as práticas dos diferentes atores engajados em cada uma destas temporalidades a fim de, nas considerações finais, destacarmos os processos vivos e múltiplos atuantes na constituição de paisagens no Delta.

\section{Raízes que compõem paisagens}

Delta do Parnaíba é o nome dado à paisagem que se apresenta quando o Rio Parnaíba se abre em diversos braços na chegada ao mar, dividindo-se em um conjunto de canais com água salobra, que sofre a influência direta da variação das marés, numa área de aproximadamente $2700 \mathrm{~km}^{2}$. Por entre os canais existem aproximadamente 80 ilhas de diferentes tamanhos. Grande parte dessas ilhas é formada por terreno que se alaga e se descobre face ao movimento das marés. Uma descrição da delimitação geográfica é assim dada por uma equipe de engenheiros de pesca:

"[O Delta do Parnaíba] se origina num ponto em que o fluxo do rio se bifurca para formar dois braços, Igaraçu e Santa Rosa. Desse processo resultam igarapés que vão, entremeados a inúmeras ilhas, terminar no oceano por meio de cinco grandes bocas com o seguinte posicionamento de leste para oeste: Tutóia, Melanciera (também chamada de Carrapato), Ilha do Caju, Ilha das Canárias e Igaraçu" (Farias et al 2015: 24).

Aí ocorrem os manguezais, que formam a grande parte da cobertura vegetal do Delta. Além dos manguezais, há, nas ilhas, áreas de terra firme, que são influenciadas, por sua vez, pela movimentação 
da areia pela força do vento, produzindo dunas em algumas delas. A vegetação de terra firme inclui áreas arenosas com lagoas temporárias, com vegetação formada por espécies características de restinga, cerrado e caatinga, tais como muricis, carnaúbas, vassourinhas, guajirus, palmas, cactos e uma diversidade de plantas arbustivas. Há também áreas de floresta. Segundo Vale \& Schaeffer-Novelli, o Delta apresenta, além de manguezais, "outros tipos de vegetação, tais como a vegetação pioneira psamófila, vegetação halofítica gramíneo-herbácea, a vegetação sub-perenifólia de dunas, entre outras" (2018:40).

O geógrafo Aziz Ab'Saber assim descreve a paisagem do Delta:

"Nesse setor, situado entre a costa nordeste do Maranhão e noroeste do Ceará, o rio Magu, no passado recente, e o Parnaíba, em atividade, respondem por um dédalo de canais entrelaçados constituído por ilhas e furos entre uma retroterra de tabuleiros rasos e antigas ilhas. Um cenário hoje mascarado pelo crescimento das planícies de marés com mangues e praias leste-oeste sincopadas de areia alvas. [...] As restingas em processo de formação orientam-se de leste para oeste encarcerando o emaranhado fluvioestuarino dos manguezais interpostos entre a praia e a terra firme do raso tabuleiro" (Ab'Sáber 2001:105).

O Delta faz a divisa litorânea dos estados do Piauí e Maranhão, na porção ocidental do Semiárido nordestino. A água doce do Rio Parnaíba vem dos tributários que nele deságuam ao longo do sertão piauiense, por quase $1500 \mathrm{~km}$, passando pela capital, Teresina, e chegando na cidade de Parnaíba. Nesta altura, onde o Delta se abre, a água fluvial passa a sofrer influência da água do mar, a partir do movimento das marés. O nível de salinidade aumenta à medida que se aproxima do mar. Isso faz com que os organismos que habitam as águas do Delta sejam adaptados à variação de salinidade.

No caso dos peixes, a heterogeneidade do ambiente permite a coexistência de animais marinhos e de água doce, bem adaptados à salinidade variável. A presença de substratos arenosos, lodosos, rochosos e de corais faz com que ocorram microambientes propícios a diferentes espécies de peixes (Lima 2012). O ambiente formado pelas raízes de 
mangue é em si um local atrativo para muitos tipos de organismos (Lacerda 2002). A grande quantidade de matéria orgânica presente, trazida pelos rios e produzida pelas árvores do manguezal, aliada à diversidade de ambientes, favorece a proliferação da vida (Schelske \& Odum 1962; Day Jr. at al 2013). Assim, as águas do Delta são lugar de encontro entre os peixes do rio e do mar, em especial local de desova e/ou crescimento de muitas espécies que são marinhas em sua vida adulta (Lima 2012).

As formações de manguezal são especialmente importantes na paisagem do Delta. As árvores de mangue são especializadas em habitar ambientes alagados, salinizados e saturados de matéria orgânica. São poucas as espécies de árvore que tem capacidade de viver em um ambiente tão específico, precisando de estratégias fisiológicas para lidar com a falta de oxigênio do solo, o excesso de sal e a instabilidade do solo lodoso. No Delta são três as espécies que ocorrem nas faixas de maior salinidade, o mangue vermelho (Rizophora mangle), a siriba (Avicennia sp.) e o mangue manso (Laguncularia racemosa). Há ainda outras espécies que ocorrem na faixas de menor salinidade, à medida que se avança rio acima, tais como o mangue de botão (Conocarpus erectus), o avencão (Acrostichum aureum) e o algodão da praia (Hibiscus tiliaceus) (Araújo et al 2018).

O mangue vermelho apresenta raízes conhecidas como rizóforos, grossas, aéreas e espalhadas, saltando para fora da terra, que a ajudam a se fixar no solo lamacento (Schaeffer Novelli 2018; Souto 2004) e também estruturas respiratórias (Cavalcanti 2004). Elas fornecem sustentação para os seus próprios troncos e copas e formam, junto a suas árvores vizinhas da mesma espécie, uma rede de rizóforos que segura os sedimentos, o que garante maior estabilidade do solo encharcado.

Além do mangue vermelho, a siriba também apresenta raízes estruturantes. São raízes radiais especializadas, que lidam com a pobreza de oxigênio do solo de forma diferente, tendo estruturas chamadas pneumatóforos que crescem de baixo para cima, rompem as camadas de terra e ficam expostas ao ar. Segundo Cavalcanti (2004), no Delta 
do Parnaíba o mangue vermelho ocorre associado a áreas de lama expostas permanentemente às marés, enquanto as siribas proliferam em áreas um pouco mais arenosas, sujeitas apenas às marés altas. $\mathrm{O}$ mangue manso ocorre em áreas ainda mais arenosas, sujeitas mais ocasionalmente às marés.

As árvores de mangue, portanto, produzem uma estrutura de solo que garante a existência de uma série de outros animais entre suas raízes (moluscos, peixes e caranguejos, por exemplo), e em seus troncos e copas (pássaros, abelhas, vespas, formigas, moluscos e aratus), bem como toda uma fauna de mamíferos e répteis que se alimentam dos animais que vivem nos manguezais, tais como guaxinins, macacos-prego, raposas, gaviões e serpentes. Esse ambiente em movimento também é habitado por outros seres microscópicos, como bactérias, fungos e algas típicos do manguezal, além de larvas de invertebrados e peixes, que vivem associadas à água e ao sedimento.

A região do Delta também é habitada por seres humanos que produzem historicamente sua paisagem. Várias das ilhas apresentam povoados formados por moradores geralmente aparentados, que têm seu modo de vida ligado à vida que pulsa no mangue e nos outros elementos da paisagem do Delta.

O acesso às povoações da principal ilha do Delta - a Ilha das Canárias - é feito pelos rios, tanto a partir do porto dos Tatus, em Ilha Grande, no Piauí, quanto pela cidade de Araioses, no Maranhão, por barcos de linha ou dos próprios moradores ${ }^{4}$. A ilha das Canárias está situada na zona rural do município de Araioses, no Maranhão e abriga as comunidades Canárias, Passarinho, Caiçara, Torto e Morro do Meio ${ }^{5}$. Destacamos ainda o povoado de Carnaubeiras, importante comunidade pesqueira também situada neste município.

O modo de existir destes humanos, em termos demográficos, espaciais e socioeconômicos, teve variações ao longo do tempo, assim como a própria configuração da paisagem, como indicamos neste artigo. Entretanto, há uma continuidade em termos de um regime de produção de conhecimento (Carneiro da Cunha 2009) sobre a paisa- 
gem do Delta, seus animais, plantas, marés, solos, ventos, estações do ano. Pesca e extração de organismos do manguezal e das vegetações terrestres, pequena agricultura e pequena criação de animais fazem parte das atividades costumeiras, tradicionais, destes habitantes.

Os caranguejos (Ucides cordatus) em especial, abundantes nos manguezais e de grande valor alimentar, têm seu modo de existir entrelaçado com os modos humanos há um longo tempo. O conhecimento sobre os modos de existir dos caranguejos é praticado cotidianamente por muitos moradores do Delta. Os seres humanos que capturam os caranguejos nos manguezais conhecem sua anatomia, a arquitetura de seus buracos, seu comportamento, seus ciclos vitais. Os caranguejos provavelmente reconhecem os humanos, com seus aparatos perceptivos próprios, no mínimo, por meio de sua relação de predação. As histórias entrelaçadas dos seres humanos e caranguejos, na paisagem do Delta do Parnaíba, remete à noção de espécies companheiras proposta por Donna Haraway, que se refere a uma vida interespécies em relação, que se apresenta por diferenças irredutiveis, relações estas que podem envolver aspectos de crueldade, indiferença, ignorância e perda, mas também alegria, transformações, colaboração e inteligência (Haraway 2003).

\section{Caranguejo é bicho sabido}

Se você mora em alguma das ilhas do Delta, há pelo menos duas formas de chegar ao mangue. Você pode ir por água - de canoa - ou ir por terra, caminhando. No ritmo do caminhar, a sucessão das paisagens é lenta e mais diversa. Saindo da casa de Sílvio - caranguejeiro morador da comunidade do Torto que irá nos guiar nesta andança pelos mangues - atravessamos o seu quintal, onde ele e o filho criam algumas cabras. Depois, chegamos às vargens que, no inverno, ficam cheias de água em suas partes mais baixas. Os juncos dominam as áreas mais alagadiças e há um sem número de caramujos chamados aruás, com os quais é preciso tomar cuidado caso esteja descalço. A concha desse molusco pode nos cortar o pé. 
Andando com Sílvio, percorremos pequenas veredas de areia, ladeadas por uma vegetação de restinga. Vassourinha, cactos, palma, mandacaru, xique xique, jenipapo, muricis, guajirus. Há várias carnaúbas, também conhecida como 'a árvore da vida', porque dela tudo se aproveita. Com a madeira constrói-se cercas, bases para hortas suspensas, bancos e um sem número de outras coisas. O mais valioso da carnaúba, contudo, está nas suas palhas, das quais se extrai o pó que será vendido às indústrias para a fabricação de velas, microchips, vinis, placas de computadores e outros ítens.

No final do verão e início do inverno (meados de setembro ao final de janeiro), Sílvio e outros caranguejeiros alternam suas atividades de trabalho entre o mangue e o carnaubal. Andar pelos carnaubais, isto é, pelas vargens repletas de carnaúbas, contudo, é uma atividade regular para vários trabalhadores do manguezal. São por esses caminhos que se chega ou se sai do raizal, como também é chamado. Além disso, se você pega caranguejos, é preciso ter palhas de carnaúba durante todo o ano, pois é com elas que esses crustáceos são amarrados. Uma corda de caranguejos, no Delta, é um acoplado de quatro bichos superpostos unidos pelos fios da palha. Ślvio leva para o mangue um número de palhas aproximado do número de cordas que pretende pegar. Costuma andar com algumas a mais, nunca a menos. Eventualmente elas podem quebrar - seja porque estão fracas ou porque um caranguejo se mexeu mais do que deveria - ou, com sorte, Sílvio pode encontrar mais caranguejos do que imaginava.

Todo esse preparo das palhas é feito ainda em casa. Nosso anfitrião as carrega amarradas à cintura enquanto caminhamos. Passamos ainda por algumas lagoas e por porções de mangue vermelho morto, raízes secas sobre a areia branca. Chegamos, então, no pé do brejo, parte de terra alagadiça que marca a fronteira entre as vargens e o manguezal propriamente dito. Um passo e já deixamos de pisar na areia fina para entrarmos num terreno completamente alagado, lamacento e com predominância do mangue siriba. 
O canto de pássaros é uma constante ao andarmos pelo manguezal. São muitas as aves presentes no mangue, algumas, inclusive, se alimentam de caranguejo, como alguns dos vários tipos de gaviões: gavião-pinhé (também conhecido como gavião- carrapateiro), gavião -pombo, gavião-galinha, gavião-misera. O barulho dos nossos passos se misturam ainda com vários outros, como os assobios e grunhidos de macacos-pregos a pularem nas copas das árvores. Com eles, todo cuidado é pouco se você está pegando caranguejos. Costumam roubar cordas dos bichos já capturados. Os sons são indicativos de sua presença nem sempre vista, mas certa.

Houvimos várias histórias envolvendo esses primatas, como no dia em que, por descuido, um deles acabou tendo a pata presa entre as conchas de uma ostra. Ou quando, surpreendido por um catador enquanto roubava seus caranguejos, o macaco ficou passando a mão na cabeça e nos olhos num gesto angustiado que parecia "pedir misericórdia”, como traduziu um interlocutor. Os macacos gritam com frequência e enquanto caminhamos ouvimos ainda o vento sacudindo o siribal, fazendo as madeiras rangerem.

Ao andar sobre uma área de siriba sente-se perfeitamente a rede de raízes embaixo dos pés. Nas áreas de mangue vermelho as passadas humanas afundam-se na lama até encontrar algum apoio em uma raiz submersa, com o risco do caminhante cortar-se com a concha de uma ostra aderida às raízes. Sílvio confessou gostar mais de trabalhar em manguezais onde a siriba predomina, porque não se sente muito confortável tendo que andar se equilibrando constantemente - o que ocorre em manguezais com maior predominância de mangues vermelhos. Mas há quem prefira o contrário e se dê melhor trabalhando em manguezais mais fechados.

Além dessas especificidades do caminhar, há outros fatores que levam Sílvio e outros caranguejeiros a preferirem trabalhar em certos locais em detrimento de outros. "Cada mangue é um mangue"6. Isso implica não só na composição de espécies vegetais como também nas particularidades dos caranguejos presentes nesses ambientes. As áreas 
que possuem caranguejos maiores, portanto mais vendáveis, são de amplo conhecimento dos caranguejeiros.

Sílvio escolheu o mangal do pé do brejo porque lá, entre outras coisas, é possível encontrar caranguejo médio-bom com (relativa) maior facilidade. Crustáceos considerados médio-bom costumam medir entre sete e nove centímetros. Sílvio ensinou como o tamanho do caranguejo tem a ver com a menor ou maior incidência de águas doces, salobras ou salgadas em determinada região. Os caranguejos situados em áreas mais afastadas do mar e, portanto, menos sujeitas a fluxos de águas com altos índices de salinidade, geralmente atingem dimensões maiores em sua fase adulta. Apesar de grandes, os caranguejos de manguezais com maior influência do doce - conforme Sílvio costuma falar - são menos gostosos que os do salgado. No comércio do caranguejo, contudo, tamanho é mais importante que sabor.

Pegar caranguejos grandes requer mais esforço e atenção. É preciso saber decifrar as pistas deixadas na lama. Os crustáceos são identificados por montículos de terra deixados para trás na entrada de suas galerias. Somente os machos são capturados. Sílvio contou-me que as fêmeas, além de serem consideradas pequenas demais para o consumo, são a garantia da continuidade da espécie (e consequentemente da atividade de cata). Elas devem ser deixadas no manguezal. Identificá-las é fácil: seus rastros sobre os montículos de lama são finos e estreitos, como pequenos arranhões na superfície da terra. Os machos, por sua vez, deixam rastros maiores e mais largos, porque seus movimentos são pesados e mais lentos, conforme observou Sílvio. Mas como identificar um caranguejo (macho) grande em meio a tantos buracos? Há nisto mais uma sofisticação técnica do trabalho dos caranguejeiros: a educação do olhar.

Inicialmente pensei que quanto maior o montículo de terra deixado para trás, maior seria o caranguejo. Logo Sílvio tratou de me apontar vários casos nos quais isso não se aplicava, mostrando-me caranguejos miúdos capturados em buracos relativamente grandes. Disse-me que, mais certeiro do que me guiar apenas pelo monte de 
lama, era analisar a espessura dos rastros e a grossura das fezes do caranguejo deixadas na boca do buraco. Demorei a conseguir diferenciar as bostas dos caranguejos de pequenos gravetos de madeira ou mesmo da lama. Elas são pequenos cilindros marrons medindo cerca de um centímetro e nem sempre estão visíveis (ao pesquisador, pelo menos). "Caranguejo é bicho que engana a gente, mas a gente tem que ser mais sabido do que ele", orientou o nosso anfitrião.

As artimanhas dos caranguejos para fugir de seus predadores humanos são várias. Eles dão pistas erradas sobre o seu tamanho real. Confundem quando parecem estar se dirigindo para um lado mas, na verdade, sua toca foi cavada por outro caminho. Eles ainda se escondem sob rebancos de areia no interior de sua galeria, ficando completamente inalcançável para o catador. Segundo Sílvio, isso é prova inconteste da inteligência desses bichos, que, ainda de acordo com ele, têm aprendido a fazer tocas mais profundas do que antigamente. "Os caranguejos estão mais fundos", afirmativa recorrente, praticamente unânime entre os caranguejeiros com quem conversamos. Mas porque isso? Sílvio respondeu: "é se escondendo".

Os caranguejeiros que acompanhamos utilizavam-se basicamente de dois procedimentos complementares: o braceamento e o uso do cambito ${ }^{7}$. O braceamento é a técnica de introdução do braço na galeria do caranguejo a fim de pegá-lo com a mão. Já o cambito, conhecido também como gancho em alguns lugares do Brasil, é uma espécie de vergalhão de ferro medindo cerca de um metro e meio e assemelhando-se a letra 'J'. Ele possui uma dobra em uma das suas extremidades responsável pela captura do caranguejo. $\mathrm{O}$ cambito pode ser visto como uma extensão do braço, auxiliar à captura por braceamento, já que é usado para obrigar o caranguejo a subir até que fique a uma profundidade que possa ser alcançada pelo braço.

No Delta, os caranguejos são dispostos em cordas logo após a captura. A corda, como referido acima, é um conjunto de quatro caranguejos, amarrados um sobre o outro com a palha de carnaúba. $\mathrm{O}$ ato de organizar os crustáceos na palha - fazer a corda - chama-se amarrar. 
Pegar caranguejo única e exclusivamente no braço nos fala de um tempo em que esses bichos eram mais bestas - no sentido de ingênuos, bobos, conforme falou nosso anfitrião. Sílvio tem quarenta e um anos e começou na cata do caranguejo ainda na infância, acompanhando parceiros mais velhos na atividade e, sobretudo, o seu padrasto. Nesta época, os oito-nove anos de Sílvio apenas amarravam os caranguejos na palha, seguindo seu mais velho por onde quer que ele andasse. Só depois de três anos na função de amarrador, Sílvio começou a pegar seus próprios caranguejos. Antes disso, apenas "brincava de pegar", enquanto era orientado por seu padrasto. Os doze-treze anos de Sílvio conseguiam capturar o bicho antes mesmo de a lama ultrapassar seu antebraço. Os tempos eram outros.

Sílvio conta que, em seu início, na adolescência, pegava cerca de trinta cordas em um dia de trabalho e ficava a chorar no mangue, esperando algum mais velho passar. Seu corpo de menino não dava conta de carregar tanto peso até a canoa. Era comum encontrar mais de um caranguejo por buraco, assim como vê-los saindo de suas tocas espantados pelo simples barulho que Sílvio fazia ao caminhar.

"Tinha muito caranguejo! Hoje eles estão ficando mais difícil". Sílvio disse ainda que isso é normal, até ele mesmo procuraria meios de se proteger caso se visse terrivelmente ameaçado, explicou. Nas palavras de um antigo caranguejeiro o que ocorre, portanto, é o seguinte: "se chega um ladrão na tua casa e rouba tudo... arromba as portas e fechaduras... O que você vai fazer? Você vai colocar uma porta melhor, mais forte, providenciar correntes e cadeados pros portões que é pra se proteger melhor. A mesma coisa é com os caranguejos". O número de caranguejeiros aumentou desde o declínio das plantações de arroz - sobre o que falaremos adiante - e, para escapar da perseguição, os caranguejos têm ficado mais espertos e feito buracos cada vez mais fundos

Os caranguejeiros com quem temos conversado - apesar de também considerarem um aumento no número de catadores - afirmam reiteradamente que as coisas são exatamente assim: caranguejos pos- 
suem um pensamento e agem de acordo com ele. "Tudo no mundo tem o seu pensar", conforme nos destacou um interlocutor. As técnicas de captura desses bichos procuram dialogar exatamente com isto: com um pensar que se faz em movimento. Os movimentos dos caranguejos, escondendo-se do mundo, fugindo de tudo, ficando mais difíceis, apontam para a existência de um mangue menos habitável do que antes. A precariedade da vida dos caranguejos e também dos caranguejeiros são fortes indicativos do capitaloceno. Esta precarização ocorre não apenas a partir da destruição e perturbarção nefasta de ambientes multiespécie. É preciso atentar também para as histórias simplificadoras que descrevem a paisagem relacionando-a exclusivamente a determinado produto econômico valorizado pelo mercado. O que subjaz a essa forma de contar e narrar paisagens?

\section{As histórias simplificadoras}

Em meados do século XVIII, a região do Delta do Parnaíba caracterizou-se pela exportação da carne seca proveniente da atividade pecuária no sertão piauiense, extensivamente desenvolvida em todo o vale do Parnaíba. Nesta dinâmica, o litoral funcionava como importante ponto de escoamento e beneficiamento da produção pastoril (Mattos 2006; ZEE do baixo Parnaíba 2002). O Porto das Barcas, situado no que mais tarde viria a ser a cidade de Parnaíba, era um importante lugar de conexão com os mercados consumidores do restante do Brasil e também do estrangeiro. Vendia-se não só a carne, mas toda sorte de manufaturados de couro, chifres e outros derivados bovinos.

O gado ocupa grande centralidade não somente na história do Delta do Parnaíba como do próprio estado do Piauí, sendo um importante vetor do processo de colonização local (Santana 1985). A apropriação das terras se dava conjuntamente ao crescimento das grandes fazendas pecuaristas, firmada a partir da expropriação das populações nativas e utilizando-se largamente de mão de obra escrava. Com o passar dos anos, a carne produzida no Piauí foi perdendo espaço no cenário nacional. Os motivos levantados por alguns historiadores variam 
desde a má administração das fazendas, até questões de falta de crédito do governo central, bem como as constantes secas que assolaram a região. No final do século XIX, consequentemente, as charqueadas deixaram de ser uma constante na região (Napoleão do Rego 2010).

O declínio do gado marcou o aparecimento de outros nichos de comércio, pautados em produtos agroextrativistas como a cera da carnaúba, o óleo de babaçu e a borracha de maniçoba. Mercado que se fortaleceu no início do século XX e trouxe diversos investidores estrangeiros para a região que, animados pela vocação comercial da cidade de Parnaíba, no Piauí, acabaram por se instalar no local e fundar importantes casas de exportação e importação de produtos locais e estrangeiros (Napoleão do Rego 2010).

Esta breve narrativa traz uma forma bastante difundida de contar histórias a respeito do lugar, a saber, através de uma nítida associação entre a região e uma série de elementos concebidos enquanto 'recursos naturais': a carne seca, a carnaúba e, mais recentemente, a paisagem turística (ZEE do baixo Parnaíba 2002), conforme falaremos adiante. Cada um desses elementos comunica sobre formas particulares de se constituir paisagem, onde o que importa é a maneira como determinados agentes humanos se mobilizam para certas atividades voltadas à extração e comercialização de um certo recurso.

Neste tipo de enfoque, os canais de água salobra, os manguezais, restingas e dunas do Delta, o vento e a força das marés, ou seja, a paisagem enquanto coletivo de seres e relações, bem como as afecções de cada uma das espécies que a habitam, raramente ocupam lugar de destaque nas narrativas. Além disso, as coletividades humanas que compõem essa paisagem tornam-se invisíveis para além de suas relações com o produto econômico da vez.

Pensamos com De Francesco et al (2017) que, ao focar demasiado nas atividades valorizadas pelo mercado em determinados momentos, este tipo de narrativa termina por vincular-se à noção de "ciclo econômico', eclipsando um conjunto de outras práticas e - conforme veremos - de conformações de paisagens também. Ao nos voltarmos 
para manguezais, caranguejos e catadores, acompanhamos grupos que habitam os territórios marginais às narrativas hegemônicas e padronizadoras a respeito do lugar.

Hoje o Delta é entendido como um polo promissor para o desenvolvimento do ecoturismo (Mattos 2006), com empresas do setor focando suas ações de marketing nas praias, dunas e lagos da região. No contexto do ecoturismo, o caranguejo passa a ocupar lugar de destaque. Festivais são feitos em sua homenagem e, neste movimento, a demanda pelo crustáceo cresceu a passos largos. Tal fato ocasionou também o aumento do número de catadores de caranguejo (caranguejeiros), que passaram a ver nos manguezais uma alternativa de renda viável. $\mathrm{O}$ desenvolvimento do potencial turístico da região, portanto, tem elevado o caranguejo à condição de principal 'recurso pesqueiro' produzido localmente (Milano 2015).

Estimou-se uma captura anual de cerca de 21 milhões de caranguejos no Delta do Parnaíba (Legat et al 2006), tamanha a importância do crustáceo para a indústria turística nordestina. Até mesmo moradores de comunidades do Delta sem histórico de envolvimento com a atividade adentraram no ramo com o passar dos anos (Mattos 2006). Assim nos explicou o sr. Carlinhos, antigo caranguejeiro e atravessador, liderança comunitária de um povoado do Delta, no munícipio de Araioses - MA, situado na Resex Marinha Delta do Parnaíba:

Eu saí da escola e parti para a área de caranguejo. [...] Formamos uma turma e trabalhava cinco na nossa canoa. E depois chegavam dois, catavam. Mas catava assim, não tinha venda de caranguejo, não. Catavam para vender nas comunidades, ou mesmo catava e botava com nós, botava na nossa canoa. Aí não era forte o catador de caranguejo no Delta. Aí depois que terminou o arroz foi que muita gente migrou para o caranguejo. Aí apareceu melhor o mercado, a venda melhor para Fortaleza, e isso trouxe muita gente. É um negócio fácil de aprender, quem pegava de comer já tava tirando normal. (Carlinhos, entrevista em maio de 2018).

Percebe-se pela fala de Carlinhos que este período foi de aumento do envolvimento comercial com a cata de caranguejos pelos morado- 
res do Delta. É importante atentar também para sua declaração de que "é um negócio fácil de aprender" (para quem já era envolvido com atividades do manguezal), pois quem já sabia "pegar de comer" também era capaz de pegar para o comércio. Destaca-se também nesta fala a demanda de caranguejos para o mercado de Fortaleza. Temos por hipótese que a demanda por caranguejos do Delta aumentou com o colapso da produção de caranguejos em áreas mais próximas a Fortaleza. Um kombista da região tornou-se então o maior comerciante de caranguejos entre o Delta e o Ceará:

Antigamente quem catava mais [era o pessoal do Catanduva], que começaram o mercado para Fortaleza. Foi o Chico, foi o cara, kombista, que começou comprando para levar para Fortaleza. Aí essas canoas vinham de Catanduva [bairro majoritariamente negro, também conhecido como um quilombo urbano, situado na periferia de Parnaíba-PI] , os catador...15 canoas, 10 canoas, no remo, para vir catar aqui e levar... aí nessa época começaram. (Carlinhos, entrevista em meio de 2018).

Parte considerável de tudo que é produzido no Delta (estados do Piauí e do Maranhão), de fato, tem como destino final as praias cearenses. A região faz parte de um famoso projeto de desenvolvimento turístico denominado de 'Rota das emoções' (Santos 2015), que envolve populações residentes nos estados do Ceará, Piauí e Maranhão. Neste contexto, o aumento da captura do caranguejo está diretamente relacionado ao crescimento desse nicho do mercado turístico, sobretudo no Ceará (Milano 2015). Assim, no Delta do Parnaíba, no final do século XX o caranguejo passa a ser o recurso da vez.

Novamente, portanto, na história do Delta, temos a atuação de forças que teimam em reduzir a complexa rede de relações entre humanos e não humanos a um único elemento que, ao ser alçado à categoria de recurso, é descolado de toda a malha de interações que o origina. Não raro ouvimos de nossos interlocutores que os caranguejos têm feito galerias cada vez mais profundas. Esta percepção dos catadores, sobre um ambiente em processo de precarização, escapa e dá novos tons ao marketing espetaculoso a respeito do "maior Delta das 
Américas'. Isso nos fala, por um lado, das lógicas por meio das quais o plantationceno/capitaloceno opera e de formas particulares de se constituir paisagem a partir do agenciamento das interações entre caranguejos, caranguejeiros e os elementos do manguezal.

Por outro lado, mostra como estes crustáceos podem até ser um produto - o que é fato, mas são, também, uma série de outras coisas e agenciam um conjunto bastante complexo de relações. Como veremos adiante, as práticas dos habitantes do Delta em interlocução com outros agentes permitem, entretanto, que os catadores não figurem apenas como submetidos à lógica predatória do capitaloceno em troca de recursos para sobrevivência.

A proeminência do ecoturismo nas narrativas sobre a região retoma, de certa forma, uma lógica que reduz a paisagem ao elemento mais valorizado pelo mercado no momento. Os manguezais passam a ser vistos em função de sua beleza cênica e como lugar de onde se extrai uma preciosa mercadoria. Esta forma de lidar e conceber o mangue varia de acordo com os sujeitos e as temporalidades envolvidas nas múltiplas formas de composição de paisagens. Há algumas décadas, por exemplo, o caranguejo era considerado uma espécie de praga e isso tem a ver com o fluxo do plantationceno ligado à presença de um elemento bastante citado pelos catadores na história recente do Delta: o arroz.

\section{Os arrozais anti-mangue}

A presença do arroz no baixo Parnaíba nos fala da historicidade e dos processos de habitação desenvolvidos localmente. Contam ainda das relações entre as pessoas, as terras e o território. As roças desse cereal, não raro, eram cultivadas em áreas de mangues desmatadas ou em lugares alagadiços. Após a retirada da cobertura nativa, começava um intenso trabalho de plantio das sementes, que dialogava com os fluxos das marés e as fases da lua. Plantava-se na maré baixa e, sobretudo, na força da lua nova, especialmente potente para processos germinativos e reprodutivos de toda e qualquer espécie. 
O cultivo de arroz, de acordo com nossos interlocutores, vigorou até a década de 1970/1980, quando já apresentava nítidos sinais de decréscimo, conforme falaremos adiante. Isso não significa dizer que seu plantio tenha deixado de existir no Baixo Parnaíba ou que as narrativas contidas aqui contemplem todo o Delta. Ressaltamos apenas o que ouvimos a respeito da relação com esse vegetal e a paisagem nas comunidades do Torto, zona rural do município de Araioses e na cidade de Parnaíba. Nesses locais o plantio do arroz perdeu força com a sucessão de diversos acontecimentos, que vão desde a desvalorização do produto no mercado da região até questões envolvendo mudanças nos índices de salinidade do rio.

As histórias e experiências com a rizicultura no Parnaíba, a depender da localidade em questão, são bastante variadas, como também o são narrativas e explicações a respeito do seu declínio. $\mathrm{O}$ arroz parece não ter sido uma cultura de grande valor de exportação no Delta, ficando restrita a uma produção por pequenos agricultores submetidos a relações de patronagem com antigos posseiros e voltada a um mercado regional (Mattos 2006; Milano 2015). Porém, era um tipo de prática que, em alguns locais, quanto mais intensificada, maior seu impacto na paisagem, por conta da remoção temporária das árvores de mangue.

De todo modo, as histórias sobre a 'época do arroz' eram frequentes entre nossos interlocutores, sobretudo para destacar as transformações da paisagem através dos tempos e, também, a fim de ressaltar a força dos manguezais na retomada de um ambiente anteriormente danificado. Se o arroz significava a aniquilação das relações multiespécies em trechos do manguezal, os mangues re-emergiram realizando processos opostos.

Agricultores e agricultoras das margens e ilhas do Parnaíba plantavam arroz no sistema de renda. Difícil precisar quando isso começou, fato apontado por outra pesquisadora (Mattos 2006). As terras e o manguezal, contudo, não eram considerados espaços coletivos ou de livre acesso, mas de apenas um único senhor autodeclarado dono ${ }^{8}$. 
Homens e mulheres deveriam pagar pelo cultivo com parte do que fora produzido. A proporção era de quatro para um: a cada quatro sacas de arroz produzidas uma deveria ser entregue ao 'dono', que possuía ainda as tecnologias necessárias para os processos de descasque dos grãos. Os arrozais, por um lado, eram a principal fonte de renda de diversas famílias ribeirinhas. Por outro, ele também era a marca do subjugo da força de trabalho dos habitantes do Delta e da plantationização da paisagem.

Dona Joana contou-me dos esforços para manter o arroz intacto frente a variedade de outros seres existentes no mangue. Hoje pescadora, ela e sua família trabalhavam exclusivamente de roça no interior do maranhão, onde morava antes de migrar para cidade de Parnaíba na sua juventude - por volta dos anos sessenta. No Piauí, onde vive até hoje, conheceu um jovem pescador e casou-se. Ela, o marido, os filhos e alguns parentes próximos passaram a se alternar entre as atividades da pesca e o cultivo dos legumes. Era um trabalho árduo, contou-me. Depois da derrubada do mangue o plantio era executado e, uma vez germinadas, as mudas de arroz deveriam ser vigiadas contras as capivaras. Dona Joana disse que seu marido e outros homens ficavam de tocaia em cima das árvores de mangue remanescentes. Munidos de pedras, paus e latas, eles faziam barulho e, por vezes, atingiam um ou outro desses animais que teimavam em destruir suas roças.

Além das capivaras, haviam outros problemas para esta e outras famílias de agricultores: os caranguejos. Estes crustáceos eram considerados 'pragas do arroz'. Aparentemente, as plantas de arroz em início de desenvolvimento eram consideradas uma iguaria para os caranguejos, que já haviam tido trechos do seu habitat de árvores de mangue destruídos para o estabelecimento dos arrozais.

A fim de lidar com esses bichos, alguns cultivadores plantavam as sementes em outro local e só transferiam as mudas de arroz para o mangue quando o broto atingia alguns centímetros. Plantava-se em carreiras - linhas paralelas de várias mudas de arroz guardando uma distância regular entre si. Uma vez crescida, a planta não era mais 
consumida por uma legião de caranguejos famintos. Nem sempre esta técnica surtia efeito, além de ser bastante trabalhosa, contaram-nos alguns interlocutores. $\mathrm{O}$ caranguejo era uma ameaça real para quem sobrevivia do arroz e dele necessitava para pagar renda. Ameaçadas, estas plantations continuaram a aniquilar outras formas de vida, além dos mangues.

A partir de um certo momento, este sistema de plantio de arroz, dependente da remoção do manguezal, ingressou na lógica da revolução verde. Não demorou muito para os agricultores começarem a utilizar agrotóxicos e pesticidas, disponíveis no comércio da região a partir das técnicas agrícolas desenvolvidas por grandes empresas agroquímicas, e incentivadas pelos governos locais 9 .

Raimundo, um antigo cultivador do município de Araioses, no Maranhão, contou-nos que o veneno era manuseado em pó e misturado às sementes de arroz numa cuia. Os trabalhadores derramavam-no sobre a terra sem fazer covas, inclusive. "E podia esperar que o arroz pegava. Bicho nenhum quebrava a palha!”, arrematou Raimundo. Ele também nos contou que, depois disso, era possível ver os caranguejos saindo dos seus buracos embriagados pelo veneno para morrerem sobre a lama logo em seguida. Mas não só os caranguejos morriam para que o arroz prosperasse. Várias outras espécies eram impactadas pelo agrotóxico, inclusive a humana. Raimundo nos relatou de alguns conhecidos seus mortos ou drasticamente adoecidos, que ele atribui ao contato direto com o produto químico.

Segundo nossos interlocutores, com o passar dos anos, num período difícil de precisar, em torno da década de 1980, a cultura do arroz foi decaindo nos manguezais do Delta do Parnaíba. As possíveis causas são várias. Para dona Joana, o aumento no número de capivaras na região depois de uma grande cheia tornou a atividade impraticável. Raimundo, por sua vez, nos apresentou uma hipótese mais difundida: as águas salgaram e, em virtude disso, os arrozais não mais produziram como antes. Ele nos contou que com a construção da barragem de Boa Esperança, no alto Parnaíba, as águas doces fluíram 
com menos força para o Delta, deixando mais espaço para a influência da água salgada. Mesmo em invernos rigorosos, as águas do baixo Parnaíba continuavam salgadas, como permanecem até hoje. $\mathrm{O}$ manguezal, então, retomou por completo seus antigos lugares, ocupando o que antes eram os arrozais. Os caranguejos também, que passaram a ser uma importante fonte de renda para os antigos agricultores.

As transformações da paisagem proporcionadas pela retomada dos manguezais, junto com os índices de salinidade da água, foram cruciais no declínio do arroz. Os mangues invadiram as antigas plantations do grão e com ele, caranguejos e caranguejeiros assumiram maior destaque nas mudanças a serem vivenciadas a partir de então. Os arrozais, portanto, marcam um tempo importante nas paisagens do Delta, sempre referida por antigos caranguejeiros.

Em contraponto às paisagens multiespécies dos manguezais, os cultivos de arroz são memórias de uma época na qual as diversidades biológica e cultural dos mangues eram dizimadas em nome da rizicultura. Essa forma de constituir paisagens é consonante com as pressões do antropoceno/plantationceno. No tempo do arroz os ambientes eram padronizados de forma a torná-los mais produtivos, ao passo que o modo de vida de ribeirinhos e caranguejeiros é, por excelência, anti-padronizador, pautando-se em uma gama bastante ampla de atividades.

\section{Modo de vida ribeirinho, políticas e desmontes no campo socioambiental}

O declínio da produção de arroz e o aumento da captura comercial de caranguejos no Delta do Parnaíba coincidiram com a emergência de preocupações em várias escalas com a conservação ambiental, que podemos ter como marco simbólico, no Brasil, a Conferência Rio-92. Uma das muitas consequências do emaranhado das redes inter-institucionais, fundos de financiamentos, mobilizações em várias escalas e coalizões que surgiram com as novas preocupações ambientais no nível institucional, foi o estímulo à criação de unidades de con- 
servação ambiental. No Delta do Parnaíba, tais processos resultaram no estabelecimento de duas unidades de conservação ambiental que ocupam praticamente todo o território do Delta, a Área de Proteção Ambiental (APA), criada em 1996, e a Reserva Extrativista (Resex) do Delta do Parnaiba, criada em 2000, área onde a maior parte de nossas pesquisas foi realizada ${ }^{10}$.

No final dos anos noventa uma movimentação política envolvendo diversos atores reivindicou a criação da Reserva Extrativista Marinha do Delta do Parnaíba. A população da área se encontra dividida em pequenos povoados, principalmente na ilha das Canárias, quais sejam: Canárias, Passarinho, Caiçara, Torto e Morro do Meio. A Resex possui pouco mais de 27.000 ha, e um perímetro aproximado de $104,931 \mathrm{Km}$.

"De acordo com o processo no 02020.000628/97-90 do IBAMA (1997), a Resex foi criada a partir das solicitações das comunidades extrativistas, através de ofícios reivindicatórios das Colônias de Pescadores, Associações de Moradores e Prefeituras Municipais de Ilha Grande, Araioses e Água Doce, reforçados por um abaixo-assinado dos moradores do município de Araioses, e oficializada através do Decreto s/no, de 16.11.2000" (Lustosa 2005:75).

A criação da Reserva Extrativista Marinha Delta do Parnaíba congregou tanto questões de justiça social - a partir da garantia do direito à terra e ao território, quanto iniciativas de preservação da biodiversidade costeira. Seu estabelecimento coincidiu com o período em que o comércio de caranguejos para o Ceará aumentou em escalas e começou a gerar preocupações com o futuro da atividade por gestores da conservação.

Com a instauração da Resex, algumas transformações foram estimuladas. Ações de reflorestamento das áreas de mangue passaram a ser incentivadas pela gestão. $\mathrm{O}$ caranguejo - de praga, conforme apresentamos na época dos arrozais - passou a ser alvo de cuidado e proteção, sobretudo com a feitura de um plano de gestão para sua extração (ICMBIO 2016). Além disso, diálogos entre técnicos do ICMBIO, pesquisadores da Embrapa e moradores da região resultaram em pro- 
postas de melhoria nas condições de transporte visando a diminuição da mortalidade dos caranguejos, que chegava a $50 \%$ dos animais, no transporte entre o Delta (Maranhão/Piauí) e Ceará (Legat et al 2003, 2006 e 2009).

O 'Plano de gestão para a extração de caranguejo-uçá em Reserva Extrativista no Delta do Parnaiba' (ICMBio 2016) nasceu de sucessivas reuniões entre órgãos ambientais, catadores, compradores e atravessadores de caranguejo. Seu principal objetivo era garantir a sustentabilidade da extração de caranguejo e, também, dos próprios manguezais. De acordo com o plano, o tamanho mínimo para a captura do caranguejo é de 7 centímetros no interior Reserva Extrativista e 6 no seu entorno, que integra a área Área de Proteção Ambiental do Delta do Parnaíba.

Além da atividade de cata do caranguejo, as formas de humanos se relacionarem com manguezais são múltiplas. Os manguezais são a base de diversos ecossistemas costeiros. Atividade essencial para maior parte das famílias do Delta é a pesca, prática que seria insustentável caso os peixes não pudessem se alimentar nas áreas de manguezal, conforme observamos com nossos interlocutores. Além disso, é dos manguezais que se extrai a matéria prima para a feitura de remédios e também para a construção de casas e canoas.

Com a instituição da Resex, as políticas de proteção a esta área ganham maior centralidade, assim como a defesa do território de povos e comunidades tradicionais no Delta. Neste sentido, o caranguejo entra como mais uma dentre as diversas atividades desenvolvidas no território. Notamos, neste processo, uma confluência, no sentido proposto por Bispo (2015), entre os interesses da gestão e o modo de vida das comunidades pesqueiras.

Além da cata do caranguejo e da pesca, as populações residentes no Delta guardam um profundo conhecimento a respeito dos ciclos de desenvolvimento da carnaúba, do caju, de ostras e de uma série de outros seres passíveis de garantir-lhes segurança alimentar e serem transformados em ganho econômico para as famílias. Nossos interlo- 
cutores ressaltavam que, apesar de qualquer dificuldade, o alimento era algo geralmente presente nas casas. $\mathrm{O}$ rio farto em peixes, as terras repletas de árvores frutíferas e havia a possibilidade do cultivo de roças. Esses elementos eram apontados a nós como prova inconteste da fartura do lugar onde viviam, da riqueza do próprio território.

A consolidação da Reserva Extrativista Marinha do Delta foi um fator de extrema importância na luta das comunidades pela proteção dos manguezais e de seu território. Parece ter avivado também, no período pesquisado, um relevante processo de participação comunitária, que não é o foco deste artigo. A consolidação da Resex retoma a relação com os manguezais a partir de parâmetros mais próximos da experiência das populações residentes localmente. A lógica das múltiplas atividades é o oposto das forças homogeneizadoras - acionadas a partir dos arrozais, mas não só - que insistem em barrar as diversidades culturais e biológicas.

Gostaríamos de terminar esta seção com uma escrita esperançosa sobre o futuro das confluências em torno da multiplicidade na paisagem do Delta. Entretanto, no momento em que este artigo é escrito, o Brasil passa por um processo agudo de transformação das políticas socioambientais, em que legislação ambiental, os direitos de povos e comunidades tradicionais, as instituições gestoras da conservação, licenciamento e fiscalização ambiental, os espaços de participação social, o financiamento de iniciativas ambientais e a própria aplicação dos instrumentos legais estão sendo desmontados drasticamente. As consequências deste processo, a longo prazo, são imprevisíveis, inclusive na paisagem do Delta do Parnaíba. Ao mesmo tempo, no final de 2019, um derramamento de óleo de grandes proporções atingiu toda a costa Nordeste do Brasil. Assim, os meses que antecederam a preparação deste artigo tornaram evidentes as catástrofes e devires de destruição do capitaloceno e nos faz pessimistas quanto à permanência das articulações animadoras entre os habitantes do Delta e os gestores da Resex Marinha do Delta do Parnaíba, que presenciamos ao longo do período de pesquisa de campo. 


\section{Vivendo em meio à perseguição}

A historiografia oficial do Delta apresenta a região como uma importante fonte de recursos, conforme referimos anteriormente. A transformação das coisas, dos viventes e dos ambientes em recursos somente é possível com a plantatificação das paisagens. Como dissemos, plantationceno e capitaloceno são outros nomes para o antropoceno (Haraway 2016). As plantations implicam em um processo de alienação através do qual os seres vivos são descolados dos seus mundos e de todo um conjunto de relações a fim de originarem recursos. Nas palavras de Tsing elas seriam "simplificações ecológicas", "ecologias evocadas para a produção do mesmo" (2019:206). A alienação ocupa um papel primordial nisso, trata-se de um trabalho ativo a fim de garantir as possibilidades da replicação.

As plantations açucareiras no Brasil são a prova disso (Tsing 2015a; 2015b; 2019). O empreendimento colonial português inaugurou nos séculos XV e XVI uma forma de lidar com a paisagem que posteriormente seria replicada por outros estados coloniais. Portugal desenvolveu uma tecnologia capaz de viabilizar a produção de cana de açúcar em larga escala através de elementos completamente desembaraçados - alienados - das relações sociais que lhes originaram. Elas se estabeleciam a custo do desflorestamento das matas nativas, escravização de pessoas africanas e desterritorialização dos povos indígenas.

O Delta, diferente das paisagens açucareiras de outras áreas do Nordeste brasileiro, permaneceu numa condição periférica ao modelo de transformação extrema das paisagens pela simplificação ecológica. Entretanto, as plantações de arroz, especialmente no período de uso intensivo de agroquímicos, se estabeleciam contra as áreas de manguezais, apresentando uma das características mais nefastas do antropoceno: a destruição dos espaços de convivência multiespécie.

Os manguezais eram cortados para o plantio das roças de arroz, cereal cuja produção era parcialmente destinada a um posseiro autoproclamado dono das ilhas do Delta, conforme relataram nossos interlocutores. A atividade de extração do caranguejo já ocorria nessa 
época, ainda que em menor quantidade. O crustáceo, contudo, era visto como uma ameaça, pois se alimentava das mudas ainda em broto e, diferente do arroz, necessitavam dos manguezais de pé para garantir a sobrevivência. A diversidade é algo ameaçador às paisagens de plantations. Os caranguejos colocavam-nas em risco e eram mortos com o auxílio de pesticidas amplamente estimulados pelos governos locais.

O plantio do arroz no manguezal, no contexto narrado, implica a supressão da ação física das raízes do mangue sobre a lama e afeta a rede de interações dela com as demais espécies do manguezal. Os caranguejos, por sua vez, instituem paisagens multiespécies pela biointeração.

Termo cunhado pelo quilombola e mestre de saberes Nêgo Bispo (Bispo 2015), a noção de biointeração nos fala de um processo de constituição pautado na convivência entre diferentes ritmos em um mesmo contexto, considerando de forma respeitosa as múltiplas formas de vidas e seres presentes. Se a alienação cria elementos desemaranhados do meio, a biointeração realiza o caminho oposto e possui no emaranhamento/envolvimento sua condição de existência e possibilidades.

Os movimentos dos caranguejos na lama oxigenam o solo, auxiliam no processo de decomposição de nutrientes. Eles se alimentam basicamente de folhas e pedaços de raízes, embora sua dieta possa incluir uma enorme variedade de matéria orgânica. Seus corpos servem de alimentos para pássaros, humanos e, inclusive, outros crustáceos - como as corredeiras (Goniopsis cruentata). Estes processos - aos quais chamamos de biointeração - fazem parte de um ciclo essencial para a constituição da dinâmica de paisagens multiespécies. Assim, caranguejos contribuem na composição de manguezais, bem como sua existência depende da conservação destas áreas. A capacidade biointerativa dos caranguejos e capivaras com o arroz, ao consumi-lo, traduziu-se na produção de pragas agrícolas a serem combatidas.

As relações dos humanos caranguejeiros com os bichos que nomeiam sua atividade passam por transformações à medida que a pai- 
sagem se transforma. Com o fim dos plantios de arroz, os caranguejos deixaram de ser uma praga. Hoje, contudo, eles estão mais fundos do que antigamente - conforme apresentamos - e isso nos dá um recado difícil de desconsiderar. A questão da esperteza dos bichos deve ser levada à sério. Não é por acaso que os caranguejos estão cavando galerias mais profundas. Para Sílvio e outros caranguejeiros, isso tem a ver com um forte sentimento de vulnerabilidade da própria vida frente a um ambiente cada vez mais hostil. É preciso se proteger diante do crescente aumento número de predadores, pensariam eles. Seja por conta do número de caranguejeiros ou não, algo mudou (pra pior) e a ação dos caranguejos - antes de tudo - diz-nos disso.

Os caranguejeiros precisam dos mangues para a manutenção de suas vidas. Em tempos de avanço da extrema direita no país e medidas governamentais que cada vez mais precarizam a vida de trabalhadores e trabalhadoras, "a maré não diz 'não há vagas"” (Silveira \& Buti 2020:144). A lida com os mangues e a maré garante segurança alimentar e renda para diversas famílias de pescadores e pescadoras artesanais. No Delta - desde os plantios do arroz, passando pela época das charqueadas e chegando na atualidade como polo de desenvolvimento do ecoturismo - manguezais, caranguejos e, sobretudo, caranguejeiros, sequer aparecem em algumas narrativas a respeito do lugar.

Conforme nos aponta Braga (2016), o ofício de caranguejeiros e seus locais de vida e trabalho sofrem com o estigma da pobreza e do atraso, ficando ao largo de narrativas históricas focadas no 'progresso' e no 'desenvolvimento econômico'. Os olhares locais a respeito dos catadores tem passado por mudanças significativas no decorrer dos anos, sobretudo com a inserção do Delta na indústria turística regional. A fundura dos caranguejos, contudo, nos fala da condição cada vez mais precária de caranguejos e caranguejeiros frente às flutuações do mercado e os circuitos econômicos da vez, sofrendo ainda com crimes ambientais e descasos governamentais que a cada dia ameaçam crustáceos e mangues. 
No final de 2019, o derramamento de óleo no litoral do nordeste levou à paralisação de diversas atividades pesqueiras. O Delta do Parnaíba, apesar de não ter sido drasticamente afetado como o litoral entre os estados da Bahia e Pernambuco, recebeu cerca de quinze toneladas em sua porção maranhense e aproximadamente dez do lado piauiense, conforme dados oficiais da Marinha e do Instituto Chico Mendes de Conservação da Biodiversidade (ICMBIO).

Acompanhamos caranguejeiros aflitos com a possibilidade de o óleo invadir grandes áreas de mangue (Coelho Pereira 2020). Seguimos catadores realizando mutirões para limpeza de suas praias, temendo que a maré levasse as manchas da costa para dentro do estuário. A preocupação era maior quando nossos interlocutores destacavam as especificidades locais: um delta situado em mar aberto e, por ser localizado próximo à linha do Equador, com uma grande amplitude de maré.

Algumas porções de mangue, sobretudo situadas nas regiões mais costeiras do Delta, chegaram a ser atingidas pelo óleo. Diferente das praias, a limpeza dessas áreas é inúmeras vezes mais complexa. Há várias ilhas sem moradores humanos no Delta, onde até mesmo o acesso por água é bastante complicado. Provavelmente mangues e regiões assim foram afetadas e não há sequer uma real dimensão da quantidade de resíduos presentes. Vale destacar ainda que a limpeza visual das manchas nem de longe significa a remoção do poluente. $\mathrm{O}$ grau de contaminação das águas e das vidas humanas e não humanas que entraram em contato com o petróleo - além das consequências disso em longo prazo - são danos que tanto caranguejeiros quanto a sociedade mais ampla ainda estão por saber. Não apenas a destruição compulsória, mas a letalidade e o adoecimento crônico em paisagens multiespécies são mais algumas das marcas do capitaloceno.

\section{Considerações finais}

Uma das principais questões trazidas pelos debates a respeito do antropoceno diz respeito a habitabilidade da Terra (Tsing 2019). É preciso criar (ou reativar) formas de existência que nos permitam en- 
frentar a destruição ao passo que também nos capacitem a produzir espaços onde a convivialidade multiespécie seja possível. Tsing (2019), então, nos aconselha a contar histórias nas quais as paisagens sejam protagonistas. Neste sentido, acreditamos que paisagem pode ser entendida tanto como um emaranhado de práticas e ritmos situados em determinado ambiente quanto uma estratégia de análise que nos orienta o olhar para as múltiplas formas de vida presentes em certos contextos. Pensar o antropoceno partindo das paisagens nos proporciona ainda perceber a multiplicidade de camadas e fragmentos que compõem o mundo através de diferentes engajamentos - humanos e não humanos.

Neste artigo falamos do Delta do Parnaíba sob diferentes experiências e perspectivas, com ênfase nas relações entre manguezais, caranguejos e caranguejeiros. As paisagens apresentam temporalidades e conformações diversas. Elas podem ser apreendidas por um olhar de fora que a caracteriza a partir do que ela possui ou não, isto é, os seus recursos naturais. Podem ter suas ecologias simplificadas, padronizadas e refeitas para barrar as diversidades cultural e biológica, como no caso das plantations de arroz. Podem ainda catalisar interesses oriundos de grupos completamente diversos, como no período de criação da Resex, quando os anseios de ambientalistas, gestores públicos e caranguejeiros convergiram na preservação do mangue e garantia dos territórios tradicionais aos pescadores.

Ao longo deste artigo, descrevemos também o estabelecimento de uma relação duradoura entre os habitantes humanos do Delta e os caranguejos, enquanto espécies companheiras, a partir do engajamento no mangue. Nos diferentes momentos que narramos, independente das forças de padronização e de 'exploração de recursos', essa relação reage com as forças de simplificação e precarização e assume diferentes configurações na produção da paisagem. Entretanto, a relação de bionteração entre humanos e caranguejos, na conformação de uma paisagem multiespécies, persiste mesmo quando forças econômicas reivindicam a uniformização da paisagem. 
Daí dizer que o caranguejo hoje é um recurso, 'mas não apenas', assim como no tempo do arroz era um inimigo, 'mas não apenas'11 (De la Cadena 2015) . O que significa dizer que os catadores de caranguejo do Delta, em seu modo bionterativo de vida, transbordam a condição a eles imposta, enquanto mão-de-obra para 'ciclos econômicos'. As conexões entre o modo de vida dos caranguejeiros, embebida em relações multiespécie, e suas relações econômicas com demandas homogeneizantes de mercado são, assim, conexões parciais (Strathern 2004). Ao longo da historicidade da paisagem do Delta atravessa-se uma relação intersubjetiva, que se estabelece no engajamento histórico dos catadores no mangue.

As histórias desses sujeitos, da esperteza dos caranguejos e das vidas que pulsam nas florestas de mangue evidenciam ambientes que se constituem a partir das práticas. Mostram como processos de biointeração formam paisagens de emaranhamentos multiespécies cotidianamente.

\section{Notas:}

1 Conceito cunhado pelo químico atmosférico Paul Crutzen e pela bióloga Eugene Stoermer para definir a era na qual a presença e atividade humana tornaramse uma força geológica e morfológica bastante significativa (Kirksey \& Helmreich 2010; Danowski \& Viveiros de Castro 2014). O termo tem passado por críticas que, inclusive, problematizam o caráter universal do humano ('antropo-') presente na expressão (Tsing 2019).

2 Segundo Donna Haraway (2016), o antropoceno é apenas mais um entre diversos nomes que podem ser utilizados para caracterizar o atual momento. Ela propõe, enquanto exercício, o uso de outros termos como 'capitaloceno', reforçando as desigualdades e destruições provocadas pelo capitalismo, ou mesmo 'plantionceno', enfatizando a ação de forças antrópicas contra florestas multiespécificas para o estabelecimento de monoculturas, geralmente às custas de mão de obra escravizada ou super explorada (Haraway 2016). Neste artigo, aceitando a proposta de Haraway e a fim de não cairmos na armadilha de um 'humano universal' cujas especificidades de raça, classe, gênero e sexualidade são eclipsadas, procuraremos evitar o termo antropoceno. Em seu lugar, iremos alternar entre 'capitaloceno' e 'plantationceno' por acreditarmos que melhor se relacionam com os tipos de processos analisados aqui. 
3 As atividades de campo que dão suporte ao artigo incluem uma viagem de campo preliminar de 10 dias realizada pelos dois autores em maio de 2018 e 12 meses de pesquisa de campo realizada pelo primeiro autor no período entre 2018 e 2020 . Quando as descrições etnográficas estiverem em primeira pessoa, tratar-se-á das experiências de campo do primeiro autor.

$4 \quad \mathrm{Na}$ Ilha das Canárias, uma das maiores do Delta, recentemente estabeleceu-se um sistema de transporte por quadriciclos em trilhas pelas restingas e dunas, o que parece ter encurtado bastante as distâncias e modificado os ritmos de mobilidade neste trecho do Delta.

5 Estes povoados fazem parte da Reserva Extrativista Marinha do Delta do Parnaíba. Além de Parnaíba, Ilha Grande (ambos no Piauí) e Araioses (MA) - localidades mais frequentadas por nós na realização da pesquisa, a Área de Proteção Ambiental do Delta do Parnaíba engloba ainda os municípios de Tutóia, Paulino Neves e Água Doce (no Maranhão), Luís Correia e Cajueiro da Praia (no Piauí), além de Chaval e Barroquinha (no Ceará).

6 Mangue, mangal e raizal são usados localmente como sinônimo de manguezal. Mangue pode se referir também a uma árvore individual, ou uma das espécies presentes. Ao longo do texto, para facilitar o entendimento, utilizamos mais frequentemente o termo manguezal para caracterizar as florestas de mangue.

7 Há várias formas de se pegar caranguejo Brasil afora. Há quem se utilize da 'redinha', uma armadilha feita com fios de ráfia e posicionada na boca do buraco. Ao sair, o caranguejo fica preso, imóvel, enganchado aos fios e, posteriormente, é pego pelo catador. Há ainda a tapagem, que consiste em soterrar o buraco, impossibilitando a saída do caranguejo e, desta forma, forçando-o a deslocar-se para mais próximo da superfície. O caranguejeiro, então, destampa o buraco e pega o caranguejo mais facilmente do que pegaria em outras circunstâncias. Na Área de Proteção Ambiental do Delta do Parnaíba a técnica da redinha é proibida e praticamente pouco utilizada entre os catadores.

8 Aparentemente em certo momento os manguezais foram apropriados por donos para fins da plantação de arroz, numa lógica que já ocorria com as áreas de terra firme, mas permanecendo de livre acesso para atividades extrativas.

9 Nossos interlocutores citaram o uso dos inseticidas Aldrin e BHC. Ambos são organoclorados com efeitos altamente deletéreos para a saúde humana e para o ambiente. Acumulam-se na gordura dos animais e ao longo da cadeia alimentar, podem provocar câncer, impedem a reprodução de alguns animais (Flores et al 2004), Ambos os inseticidas tiveram seu uso proibido no Brasil há mais de 20 anos.

10 Não há espaço aqui para discorrer sobre os processos complexos que resultaram na criação destas duas unidades de conservação ambiental. No caso da Resex, é importante destacar que esta categoria surge a partir das reivindicações de regularização fundiária por seringueiros no Acre, no final da década de 1980 (Alegretti 2002), e depois passa a ser pensada, por extensão, por gestores da conservação em diálogo com populações litorâneas, para áreas costeiras e marinhas, com um boom no período de 1999 a 2008, passando de 8 a 50 neste intervalo de tempo (Silveira et al 2011). É neste período que a Resex do Delta é criada. Uma APA permite a existência de áreas públicas e privadas de uso diverso e contro- 
lado; uma Resex é uma área pública destinada integralmente ao uso de povos e comunidades tradicionais.

11 Marisol De la Cadena relaciona a ideia de 'conexões parciais', de Strathern (2004) com a argumentação de seu interlocutor etnográfico, Mariano Turpo, de que certas coisas são algo, 'mas não apenas' (por exemplo, ser indígena). Para De la Cadena, a noção de conexões parciais "oferece a possibilidade de conceituar entidades (ou coletivos) em relações integralmente implicadas, assim rompendo com a ideia de que são unidades, permitindo assim a análise de como as formas relacionais aparecem uma dentro da outra e ao mesmo tempo permanecem distintas" (De la Cadena 2015:35).

\section{Referências:}

AB'SÁBER, Aziz. 2001. Litoral do Brasil. São Paulo: SP Produção e Comunicação. ALEGRETTI, Mary. 2002. A construção social de politicas ambientais: Chico Mendes e o movimento dos seringueiros. Tese de Doutorado. Brasília: Universidade de Brasília.

ARAÚJO, L. et al. 2018. "Structure of a disturbed mangrove in the Rio Parnaiba Delta, Piauí, Northeast Brazil.” Feddes Repertorium, 129:75-91.

ASSAD, L. et al. 2012. Industrialização do caranguejo-uçá do delta do Parnaíba. Brasília: Companhia de Desenvolvimento dos Vales do São Francisco e do Parnaíba/ Instituto Ambiental Brasil Sustentável.

BISPO, Antônio. 2015. Colonização e quilombos: modos e significados. Brasília: Instituto Nacional de Ciência e Tecnologia de Inclusão no Ensino Superior e na Pesquisa.

BRAGA, Daniel. 2016. Corp-oralidades: experiência corporal e memória de trabalhadores dos rios e dos mangues no povoado do Morros da Mariana/PI (1970-1980). Dissertação de Mestrado. Teresina: Universidade Federal do Piauí.

CARDOSO, Tiago. 2018. Paisagens em transe: ecologia da vida e cosmopolítica Pataxó no Monte Pascoal. Brasília: IEB; Mil Folhas.

CARNEIRO DA CUNHA, Manuela. 2009. Cultura com aspas e outros ensaios. São Paulo: Cosac \&Naify.

CAVALCANTI, Agostinho. 2004. "Análise integrada das unidades paisagísticas na planície deltaica do Rio Parnaíba-Piauí/Maranhão.” Mercator-Revista de Geografia da UFC, 3(6):105-118.

COELHO PEREIRA, Lucas. 2020. "E o Delta do Parnaíba? O perigo do petróleo cru não acabou". Ocorre Diário. (https://ocorrediario.com/e-o-delta-doparnaiba-o-perigo-do-petroleo-cru-nao-acabou/; acesso em 20/01/2020).

DANOWSKI, D. \& VIVEIROS DE CASTRO, E. 2014. Há mundo por vir? Ensaio sobre os medos e os fins. Florianópolis: Cultura e barbárie/ Instituto Socioambiental. 
DAY JR., J. W. et al. 2013. Estuarine Ecology. New Jersey: Wiley-Blackwell.

DE FRANCESCO, A. et al. 2017. "História de Ocupação do Beiradão no Médio Rio Xingu”. In MAGALHÃES, S. \& CARNEIRÓ DA CUNHA, M. (eds.): A Expulsão de Ribeirinhos em Belo Monte: relatório da SBPC, pp.41-65. São Paulo: SBPC.

DE LA CADENA, Marisol. 2015. Earth Beings. ecologies of practice across Andean worlds. Durham: Duke University Press.

FARIAS, A. et al. 2015. Cadeia produtiva da pesca no interior do Delta do Parnaiba e área marinha adjacente. Fortaleza: Editora RDS.

FLORES, A. et al. 2004. "Organoclorados: um problema de saúde pública". Ambiente e Sociedade, 7(2):111-124.

HARAWAY, Donna. 2003. The companion species manifesto: dogs, people and significant otherness. Chicago: Prickly Paradigm Press.

. 2016. "Antropoceno, Capitaloceno, Plantationoceno, Chthuluceno: fazendo parentes". Clima Com Cultura Científica- pesquisa, jornalismo e arte, 3(5):139-146.

ICMBio, Instituto Chico Mendes de Conservação da Biodiversidade. 2016. Plano de gestão para extração do caranguejo-uçá em Reserva Extrativista no Delta do Parnaíba. Parnaíba: Instituto Chico Mendes de Conservação da Biodiversidade.

INGOLD, Tim. 2002. The perception of the environment: essays on livelihood, dwelling and skill. London: Routledge.

. 2015. Estar Vivo: ensaios sobre movimento, conhecimento e descrição. Petrópolis: Editora Vozes.

KIRKSEY, S. \& HELMREICH, S. 2010. "The emergence of multispecies ethnography". Cult. Anthropol. 25(4):545-576.

LACERDA, Luiz Drude (ed.). 2002. Mangrove Ecosystems: function and management. Berlin: Springer-Verlag Berlin Heidelberg.

LEGAT, J. \& LEGAT, A. 2009. "Metodologia para o transporte de caranguejo vivo com baixos índices de desperdícios". Boletim Técnico Científico do CEPENE, Tamandaré, PE, 17(1):115-121.

LEGAT, J. et al. 2006. "Considerations about Ucides cordatus cordatus fishing in the Parnaiba River Delta region, Brazil”. Journal of Coastal Research, SI(39):12811283.

LEGAT, J. \& PUCHNICK, A. 2003. Sustentabilidade da Pesca do Caranguejo-uçá, Ucides Cordatus,nos estados do Piaui e do Maranhão: uma visão da cadeia produtiva do Caranguejo a partir de fóruns participativos de discussão. Parnaíba: Empresa Brasileira de Pesquisa Agropecuária.

LIMA, Eudes 2012. "Ictiofauna do Delta do Rio Parnaíba, litoral piauiense". In GUZZI, A. (ed.): Biodiversidade do Delta do Parnaíba, litoral piauiense, pp.115138. Teresina: Ed. UFPI.

LUSTOSA, Ana Helena. 2005. Práticas produtivas e (in)sustentabilidade: os catadores de caranguejo do Delta do Parnaíba. Dissertação de Mestrado. Teresina: UFPI. 
MATTOS, Flávia. 2006. Reservas Morais : estudo do modo de vida de uma comunidade na Reserva Extrativista do Delta da Parnaíba. Dissertação de Mestrado. Rio de Janeiro: Universidade Federal Rural do Rio de Janeiro.

MILANO, Claudio. 2015. Eran bichos de siete cabezas: Una isla del Delta del Parnaíba (Brasil) en la mira de la promoción turística transnacional. Tese de Doutorado. Barcelona: Universitat Autònoma de Barcelona.

NAPOLEÃO DO REGO, Junia. 2010. Dos sertões aos mares: história dos comércios e dos comerciantes de Parnaíba (1700-1950). Tese de doutorado. Rio de Janeiro: Universidade Federal Fluminense.

SANTANA, Raimundo (ed.). 1995. Piauí: Formação. Desenvolvimento. Perspectivas. Teresina: Halley.

SANTOS, Potyguara. 2015. "Territorialidades dos programas de desenvolvimento em zonas costeiras do Nordeste brasileiro: projetos de infraestrutura de grande escala em turismo (PGE-Tur), populações tradicionais marítimas e suas ações contraprogramáticas." Wamon-Revista dos alunos do Programa de PósGraduação em Antropologia Social da UFAM, 1(1):13-28.

SCHAEFFER-NOVELLI, Yara. 2018. "A diversidade do ecossistema manguezal." In Instituto Chico Mendes de Conservação da Biodiversidade (ed.): Atlas dos Manguezais do Brasil, pp. 21-54. Brasília: Instituto Chico Mendes de Conservação da Biodiversidade.

SCHELSKE, C. \& ODUM, E P. 1962. "Mechanisms maintaining high productivity in Georgia estuaries". Proc Gulf Caribb Fish Inst, 14:75-80.

SILVEIRA, P. et al. (2011). "Reservas extrativistas e pesca artesanal: etnografia do campo socioambiental em Pernambuco". Relatório de Pesquisa (Facepe e Fundação Joaquim Nabuco). (www.fundaj.gov.br/index.php/pesquisasconcluidas/2010-atualmente/227-reservas-extrativistas-e-pesca-artesanaletnografia-do-campo-socioambiental-em-pernambuco-pedro-castelobranco0-2011; acesso em 1/9/2020).

SILVEIRA, P. \& BUTI, R. 2020. "A vida e a morte dos guaiamuns: antropologia nos limites dos manguezais”. Anuário Antropológico, 45(1):117-148.

SOUTO, Francisco. 2004. A ciência que veio da lama: uma abordagem etnoecológica das relações ser humano/manguezal na comunidade pesqueira de Acupe, Santo Amaro-BA. Tese de Doutorado. São Carlos: Universidade Federal de São Carlos.

STRATHERN, Marilyn. 2004. Partial connections. Oxford: Altamira Press.

TSING, Anna. 2015a. "Margens indomáveis: cogumelos como espécies companheiras." Ilha, 17(1):177-201.

2015b. The Mushroom at the End of the World. On the possibility of life in capitalista ruins. Princeton: Princeton University Press.

.2019. Viver nas Ruinas: paisagens multiespécies no antropoceno. Brasília: IEB Mil Folhas.

ZEE do Baixo Parnaíba. 2002. Zoneamento Ecológico-Econômico do Baixo Rio Parnaiba: Subsideos técnicos. MMA/SDS, Relatório Final, Brasília. 


\begin{abstract}
The mouth of the Parnaiba River, located in northeastern Brazil between the states of Piauí and Maranhão, originates the only Delta of the Americas in the open sea. This region presents a rich socio-biodiversity and exuberant mangrove forests subject to forces of simplification and contamination characteristic of the anthropocene. The proposal is to make the landscape the protagonist of the narrative, taking into account relationships between crabs, mangroves, and crabs catchers (caranguejeiros). Through an ethnographic approach concerned with human and non-human relations, the article highlights the constitution of multispecies landscapes through historical processes. It is also thematized how academic and institutional narratives tend to eclipse biological and cultural diversities. As a counterpoint, the paper emphasizes the vivid and multiple dynamics active in the constitution of landscapes in the Delta.
\end{abstract}

Keywords: Mangroves, Burrow crabs, Ucides cordatus, Delta do Parnaiba.

Recebido em julho de 2020.

Aprovado em março 2021. 